\title{
PUBLIC KNOWLEDGE AND PERCEPTION OF CLIMATE CHANGE AND GLOBAL WARMING IN THE CONTEXT OF ENVIRONMENTAL CHALLENGES AND POLICIES IN SAUDI ARABIA
}

\author{
ABDULAZIZ I. ALMULHIM \\ Department of Urban and Regional Planning, College of Architecture and Planning, \\ Imam Abdulrahman Bin Faisal University, Saudi Arabia
}

\begin{abstract}
The adverse impacts of climate change have been experienced across the world including the Dammam City in Saudi Arabia. While there are many efforts targeted to fight climate change, their success is dependent on the public having sufficient knowledge about the issue. Hence, the fight against climate change urgently requires an increase in public awareness for effective mitigation measures. Thus, this study seeks to identify level of knowledge and awareness of the people of Dammam about climate changes, causes and impacts on humanity. The study involved 310 respondents who are residents of Dammam and gave their responses by completing an online questionnaire. The findings revealed that $90 \%$ of the respondents were aware of the contemporary climate change problem and they had acquired that knowledge from conventional sources like social media and $67 \%$ were very worried about the impacts of climate change. The results also showed that $33 \%$ had no awareness knowledge at all about the causes of climate change and its impacts. The study concluded that slightly above quarter of the respondents have good knowledge, understanding, and awareness of climate changes. The study recommends more efforts to be directed toward expanding public knowledge on climate change.

Keywords: awareness, cause and impacts, climate change, knowledge, Saudi Arabia.
\end{abstract}

\section{INTRODUCTION}

Climate changes experienced globally today are mainly caused by human activities [1]. The effects of these changes, such as global warming, is on the rise in the past few years, and it is generally accepted that environmentally unfriendly human behaviour is the cause of rapid climate changes [2]. The main effect of human activities on environmental pollution is global warming. Industrialization and the carbon emission of locomotives have led to the increase of greenhouse gases in the atmosphere [3]. The use of fossil fuels, reduction of vegetation covers, and cutting down of trees have increased the carbon prints in the air, leading to the accumulation of greenhouse gases [4]. The greenhouse gases are responsible for the global warming in the world, which has led to climate changes [5]. The effects of climate changes vary and could result in drought, floods, and depletion of the ozone layer. The term global warming is used to illustrate the increase in temperature due to climate changes. Increased levels of temperature have been noted in the past few decades [6]. A report by United Nations on global emissions revealed that the earth is headed for temperature spike by three degrees by 2030 since pre-industrial levels [7]. These estimates were predicted by the Intergovernmental Panel on Climate Change (IPCC) which is a United Nation's body responsible for highlighting the changes in temperature and forecasting climate changes that might happen in the future [8]. Knowledge and awareness on climate change are essential as it involves knowing the current situation of climate change, the causes, the impacts and the role of human involvement in climate change. Up to date knowledge is obtained by conducting regular assessments and analysis of data using scientific methods. On the other hand, public awareness is created by publishing the findings of data analysis and 
interpretation of how the findings affect future risks. UN Alliance on Climate Change Education, Training and Public Awareness focuses on educating the public on issues about climate change [9]. Creating awareness allows people to understand the real problem of climate change and the need to address the issue urgently by adapting their behavior and implementing mitigation measures.

People's knowledge of climate changes is essential in adapting to the new life provided by temperature changes. Knowledge acts as a base for human decision-making [10]. Change demands that human beings adapt accordingly to the new way of life created by the changes in the ecological space. The ecological knowledge development demands practice and belief of several important components. The attainment of ecological knowledge is dependent on the transfer of knowledge from one generation to another. People's attitudes on how to act can be formed by increasing the ecological knowledge they have. The increase in knowledge of the environment will ensure the human activities that contribute to climate changes are minimized and that human life will be spared from the harm of climate changes eventually [11]. Globally, Human beings are the main contributors to global warming [12]. The activities run by human beings affect the natural resources, biodiversity and make the environment unconducive and inhabitable for living things. The solution to adverse climate conditions lies in the hands of people by reducing environmental polluting activities. The main challenge is that most people do not know that their behaviours are causing environmental problems.

It is expected that the impact of climate change will affect all parts of life within the KSA, including water, health, food production and agriculture, fisheries, biodiversity, forestry and farmed areas [13]. The Government and many components of the Saudi society, including private sector institutions, science and technology and, to a lesser extent, civil society have taken many measures to decrease adverse climate changes. In ensuring the sustainability of water resources, the KSA government has implemented various initiatives. In terms of water policies, the main objectives set in KSA's Ninth Development Plan (2010-2015) are: preservation of non-renewable water tanks in sensitive areas by limiting their usage of drinking, Established 74 dams and increasing the overall storage capacity of the country to 1,349 miniature circuit breakers, promoting the recovery and reuse of wastewater and strengthen agricultural water conservation measures [13]. The KSA attempts to ensure food security through execution of the newly developed Agriculture Strategy (2010-2030) and address the worldwide market's food shortfall while minimizing price risk through forming strategic reserves and developing programs for low-income social security network members [13]. The Agriculture Strategy (AS) also supports Saudi farming investments in partnership with countries with relatively high agricultural production. It primarily aims to produce food but also to save an irrigation water of 8.5 billion cubic metres by 2030 . Predicted adverse impacts of climate change on forest land over the coming 50 to 100 years are: increased frequency and patterns of environmental disturbances such as drought, sandstorms, fires, fluxes, increased forest and woodlands die-back, disease transmission, change in species composition and wealth, decreased biodiversity productivity. In 2009, the KSA finances the Clean Development Mechanism National Committee (CDM), which is the designated national authority in the KSA [13]. Besides these sectors, Saudi also experiencing climate changes due to oil pollution and carbon emissions. KSA is attempting to minimize greenhouse emissions and producing cleaner fuels by enhancing refineries. The Kingdom also supports climate change mitigation by improving and distributing solar energy from the year of 2020 [13]. The Madinah Landfill Gas Capture project, carried out with the technical help of Swiss company Vitol with in the KSA and aims at fostering best practices in waste management, contributes to the transfer of technology and reduces greenhouse gas emissions [13]. It is important to raise people's awareness and knowledge about climate change to 
preserve all of Saudi Arabia's climate and inexhaustible resources. People, with proper knowledge and perception towards climate change, therefore, can help the government to save the environment. This research will explore public knowledge and perception of climate change in the context of environmental challenges and policies in Saudi Arabia. Human beings represent the main stakeholders in reducing adverse conditions of climate change because their decisions will determine how the climate conditions are reduced [14]. According to Wolf and Moser [15], mitigation efforts can be made only if all populations are aware of the impact of climate change. Providence of information about climate change and creating awareness of it to all people will fasten the process of curbing climate change. There must be a distinction between those who understand, perceive, and assume responsibility for climate change.

\section{MATERIALS AND METHODS}

The study analyses the research output of the Dammam city. Dammam city is the largest city and is the capital of Saudi Arabia's Eastern Province region. It is bordering with the Arabian Gulf, and is $380 \mathrm{~km}$ away from national capital, Riyadh [16]. Dammam possesses numerous oil reserves, and their discovery in 1,938 led to the rapid development of the region from a small postal settlement to a major seaport. It is also one of the hubs of natural gas and petroleum centers in Saudi Arabia. As per 2021 statistics, a total of 1,279,000 people were residing in the city of Dammam [17]. The area covered by the city is approximately $800 \mathrm{~km}^{2}$. The total GDP per capita of this city was USD 23,352 in the year 2020 [17]. The research used quantitative methods to collect and analyse data. A particular, a questionnaire was used to collect data from the respondents. The questionnaires were deployed using the QuestionPro between January and March 2021 (www.questionpro.com). online surveys were chosen because are faster, less costly, and protect the confidentiality of the respondents [18]. The sample population was obtained using snowball sampling method. Also, snowball sampling was applied to distribute the link to the survey via email and social media, with the recipients of the survey link sharing it with their acquaintances living in the area. By the end of March, the number of people that had expressed their willingness to participate in the study was 310 individuals. That number was considered sufficient based on the Cochran's formula given that the city has a population of 1.17 million people and significance level adopted was 0.05 [19]. Notably, only those that willingly volunteered to participate in the study were included in the final sample population. Caution was taken to protect the confidentiality of the respondents. That was achieved through the application of the snowball sampling technique which enables a researcher to study a huge population anonymously with a high response rate [20]. The method was critical in reaching out to participants and distributing the questionnaires, especially to female respondents [21]. According to Saudi Arabia's cultural norms, there are rules that guide social interactions especially those between opposite sex and breaking these rules could offend the population being investigated [22], [23]. In addition, the survey was conducted during the COVID-19 pandemic, a period where field surveys have become problematic hence online survey was the best alternative [24].

The study examined the awareness the Dammam city residents have of climate changes. The investigation had a broad scope from knowing whether they knew the differences between weather and climate, causes of climate conditions, effects of climate changes, possible remedies to global warming, and ways of reducing the carbon emitted into the atmosphere. The study opted to use a close-ended questionnaire that was grouped into four distinct sections. The questionnaire contained several important sections that constituted the different aspects of information required for the survey. The age, education, and social information of the respondents dominated the first part of the questionnaire. The research 
also wished to find out how many people in the city had heard of global warming or climate change. This information was included in the self-reported knowledge section of the questionnaire. It was also important to inquire if they had any beliefs about climate change and whether they were worried. Three elements 0,1 , and 2 were used to analyze the beliefs of the respondents on climate changes ("0" referred to people who believed supernatural forces cause climate changes, "1" depicted the ones who believed nothing supernatural controlled climate changes, while " 2 " represented those who were not sure whether supernatural beings affected climate conditions or not). The study assessed the residents' knowledge of the "greenhouse effect" and how conversant they were about its effects. The questionnaire provided four options on the level of knowledge on the greenhouse effect. It was also essential to know what percentage of people in Dammam could differentiate between weather and climate. The information on how they could distinguish the two was important in knowing how aware and knowledgeable they are. The Dammam city residents' knowledge of fossil fuels and their effects were investigated in the study. The sample of 310 respondents was expected to explain whether they knew what fossil fuels are and their effect on the environment. The final part of the questionnaire contained questions that tested whether the respondents understood the causes and impact of climate changes and the recommendations to the problems arising from these changes. The questionnaire gave numbers between 1 to 5 indicating how knowledgeable one is on the causes and impact of climate changes $(1=$ not knowledgeable at all; $2=$ a little knowledgeable; $3=$ moderately knowledgeable; $4=$ knowledgeable on the causes but not very knowledgeable on effects of climate conditions; and $5=$ knowledgeable in both causes and effects of climate conditions).

Reliability analysis was conducted for the questionnaire of the study on the pilot sample of (30) respondents, we used Cronbach's alpha and Pearson's Correlation for internal consistency and validity. Results of Cronbach's Alpha shown in Table 1 below.

Table 1: Cronbach's alpha reliability result.

\begin{tabular}{|l|c|c|}
\hline \multirow{2}{*}{ Questionnaire items } & No. items & Cronbach's Alpha \\
\cline { 2 - 3 } & 6 & 0.761 \\
\hline
\end{tabular}

For the pilot data collection the sample size was (30) respondents, the calculated Cronbach's Alpha was (0.761) for Likert items in the questionnaire (6 items); this results indicate a good reliability for the questionnaire, Cronbach's alpha ranges from $r=0$ to 1 , with $\mathrm{r}=0.7$ or greater considered as sufficiently reliable [25]. For reliability analysis, "the tendency towards consistency found in repeated measurements of the same phenomenon is referred to as reliability" [26]. Thus, the researcher may be sure of the validity and reliability of the questionnaire and thus became suitable for the application of the all sample. Pearson's correlation was conducted to assure the validity between each item and the total degree of the questionnaire. Results shown in Table 2.

Table 2 shows the acceptable internal consistency for all statements of the questionnaire, from which we found that all correlation coefficient $(r)>0$, ranged between 0.351 as minimum value and 0.670 as maximum value. According to Cohen [27]; $(\mathrm{r}=0.10 ;$ small, $\mathrm{r}$ $=0.30$ medium, $r=0.50$ large). All Pearson's correlation coefficient significant with $p$-value $\leq 0.05$. 
Table 2: Acceptable internal consistency for the items of the questionnaire.

\begin{tabular}{|l|c|c|c|}
\hline & $\begin{array}{c}\text { Scale mean } \\
\text { if item } \\
\text { deleted }\end{array}$ & $\begin{array}{c}\text { Scale } \\
\text { variance if } \\
\text { item deleted }\end{array}$ & $\begin{array}{c}\text { Corrected } \\
\text { item-total } \\
\text { correlation }\end{array}$ \\
\hline $\begin{array}{l}\text { 1. Knowledge of the difference } \\
\text { between climate and weather among } \\
\text { the respondents }\end{array}$ & 13.67 & 13.333 & 0.351 \\
\hline $\begin{array}{l}\text { 2. Level of worry regarding climate } \\
\text { change among the respondents }\end{array}$ & 13.67 & 11.885 & 0.582 \\
\hline $\begin{array}{l}\text { 3. Beliefs regarding the causes of } \\
\text { climate change among the } \\
\text { respondents }\end{array}$ & 14.20 & 13.959 & 0.472 \\
\hline $\begin{array}{l}\text { 4. Level of understanding regarding } \\
\text { greenhouse effect among the } \\
\text { respondents }\end{array}$ & 13.67 & 11.540 & 0.556 \\
\hline $\begin{array}{l}\text { 5. Awareness of respondents on the } \\
\text { nature and effect of fossil fuels on the } \\
\text { environment }\end{array}$ & 13.67 & 11.195 & 0.670 \\
\hline $\begin{array}{l}\text { 6. Awareness of knowledge of causes } \\
\text { and impact of climate change among } \\
\text { the respondents }\end{array}$ & 13.47 & 11.775 & 0.443 \\
\hline
\end{tabular}

\section{RESULTS}

The data collected were analyzed using the SPSS software package (IBM, Armonk, NY, USA). This statistical package is mainly used to analyze descriptive statistical data [28]. The software produced analyzed data after calculating the mean, frequencies, and standard deviation. Fig. 1 displays the education level of the respondents of the online questionnaire. The respondents varied from people who had a primary level of education to those who had

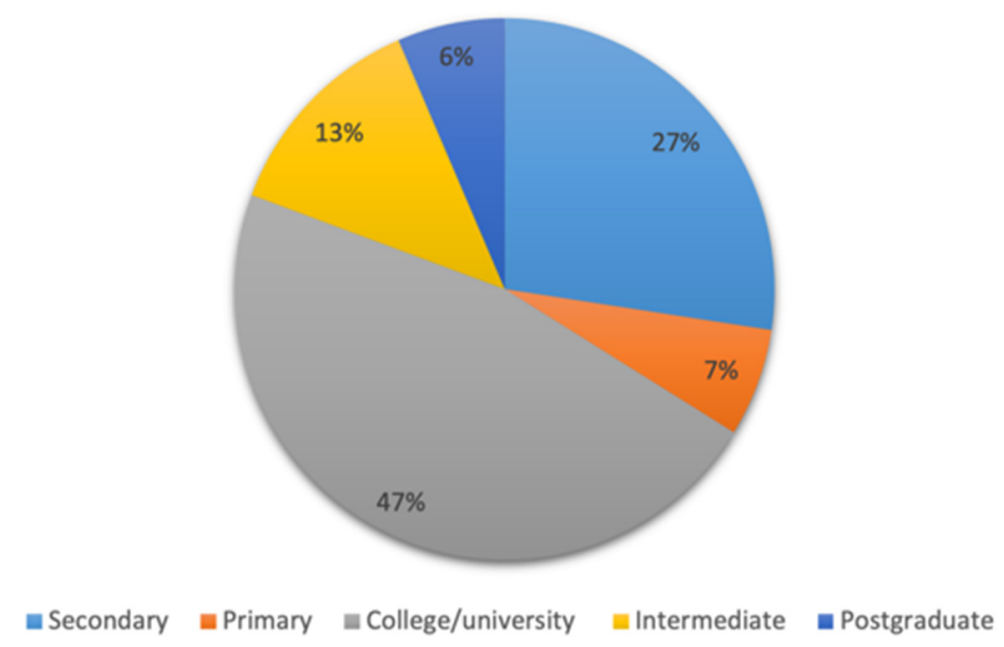

Figure 1: Level of education the respondents. 
college/university level education. $47 \%$ of the respondents had college and university-level education, while $7 \%$ of respondents had only primary levels of education. The conclusion from this was nearly half of the respondents have university or college level degree which shows that they may acquire knowledge from their school level or college level education regarding climate changes at one point of time. The self-reported knowledge of climate changes, their impact, and their effects on human life are represented in Fig. 2. A very high percentage (90\%) of the respondents were aware, through hearing from various forums such as social media, about climate conditions and global warming. In conclusion to this figure, most of the respondents have self-reported knowledge on the climate changes.

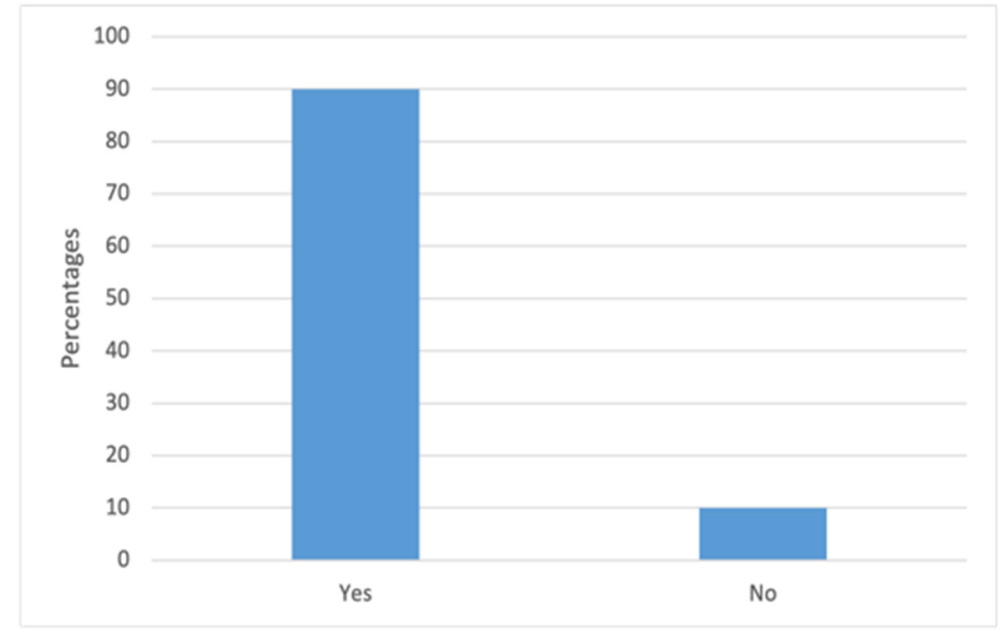

Figure 2: Self-reported knowledge on climate change among the respondents.

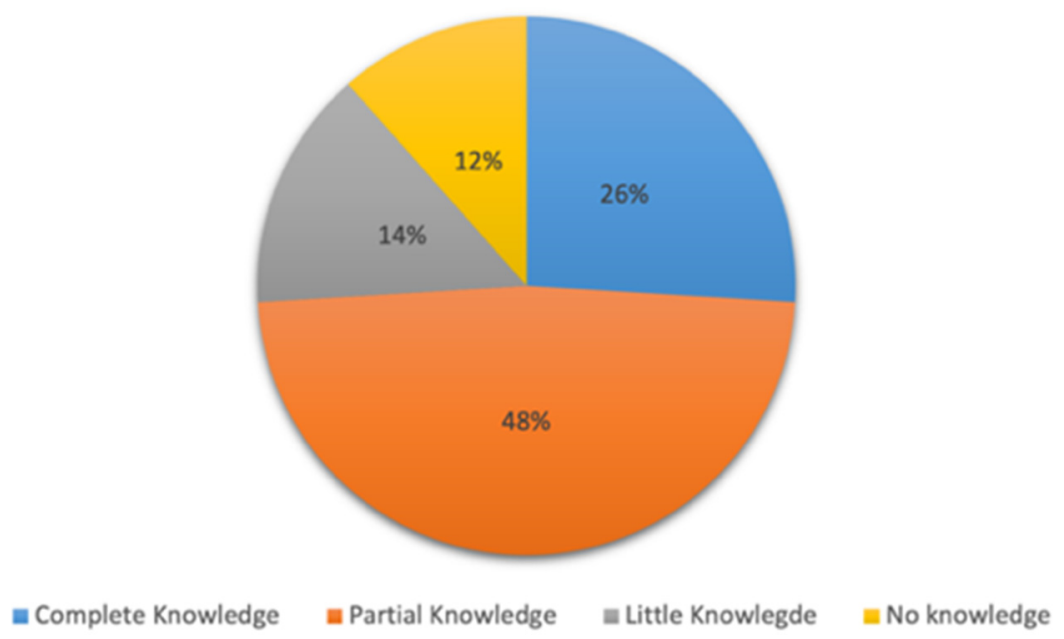

Figure 3: Knowledge of the difference between climate and weather among the respondents. 
After this, we have shown the distribution of how the respondents responded to their knowledge of the differences between weather and climate (Fig. 3). The Dammam residents who participated in the research could not clearly distinguish between weather and climate. Only $26 \%$ of the total respondents were clearly able to answer this question, while $48 \%$ had partial knowledge of the difference between these two words. From this, most of the respondents do not have accurate knowledge on the difference between climate change and weather.

After checking the respondent's knowledge, we have gone further to check the respondent's level of worriedness regarding climate change. Fig. 4 describes the level of worry among Dammam residents on the climate changes witnessed in the past few years; $67 \%$ of the residents are apprehensive about the changes in climate conditions, $7 \%$ are less worried, while $3 \%$ do not care about the issue. Thus, the level of worry is quite high among the majority of residents of Dammam, as seen from the responses given by the 310 respondents. In conclusion, most of the respondents were very worried about the climate changes.

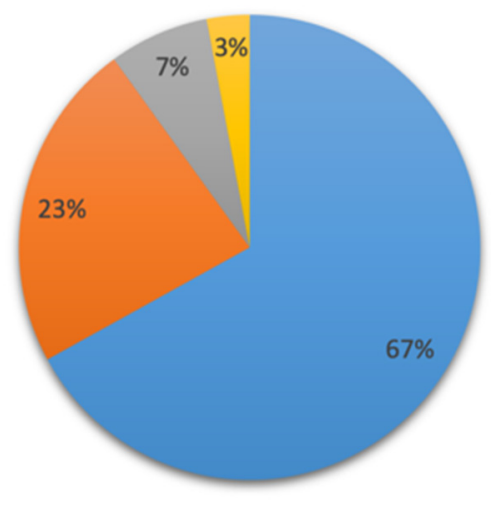

a Very worried $\quad$ Less worried Not worried Do not care

Figure 4: Level of worry regarding climate change among the respondents.

Further, we have observed the respondent's beliefs about the causes of climate change and their knowledge regarding greenhouse gases effect in the environment (Figs 5 and 6). The study displayed several abilities and knowledge levels of the Dammam city residents regarding climate change. While $10 \%$ of the respondents believed that climate changes are associated with supernatural forces, a much higher percentage $(75 \%)$ did not believe that supernatural forces were behind the existence of climate changes (Fig. 5). A total of 120 respondents out of 310 were very knowledgeable about the effect of greenhouse gases on the environment and their contribution to climate change; however, $6.4 \%$ of respondents did not have any knowledge of the greenhouse effect (Fig. 6). From these two figures, the conclusion was most of the respondents do not believe that supernatural forces were behind the existence of climate changes, instead they were aware about the greenhouse gases effects on climate change.

Along with the greenhouse gases effects, we have also checked the respondent's awareness about the fossil fuels effects on the climate. As shown in Fig. 7, less than 10\% of 


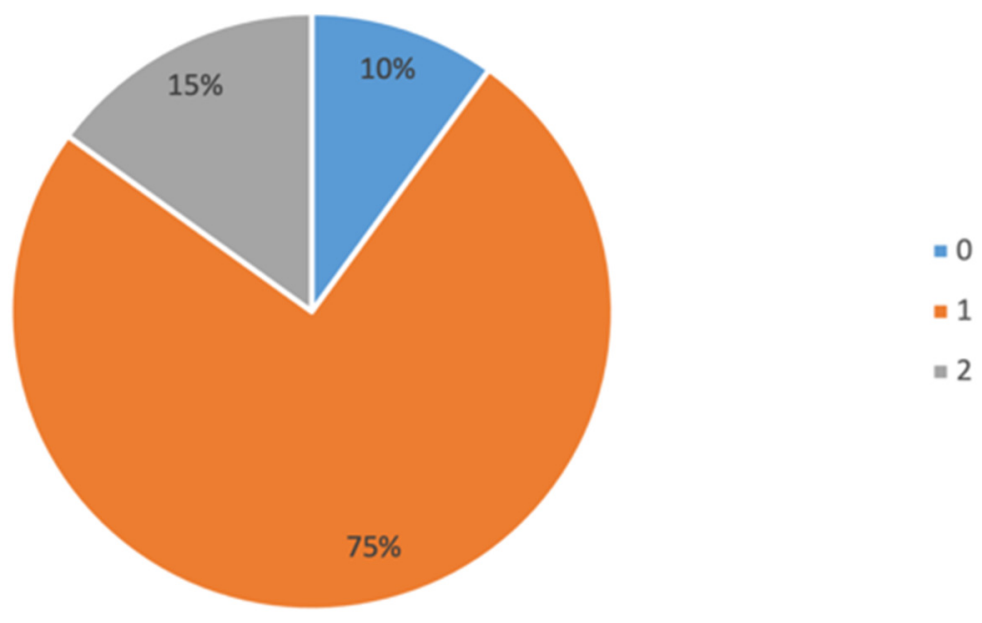

Figure 5: Beliefs regarding the causes of climate change among the respondents.

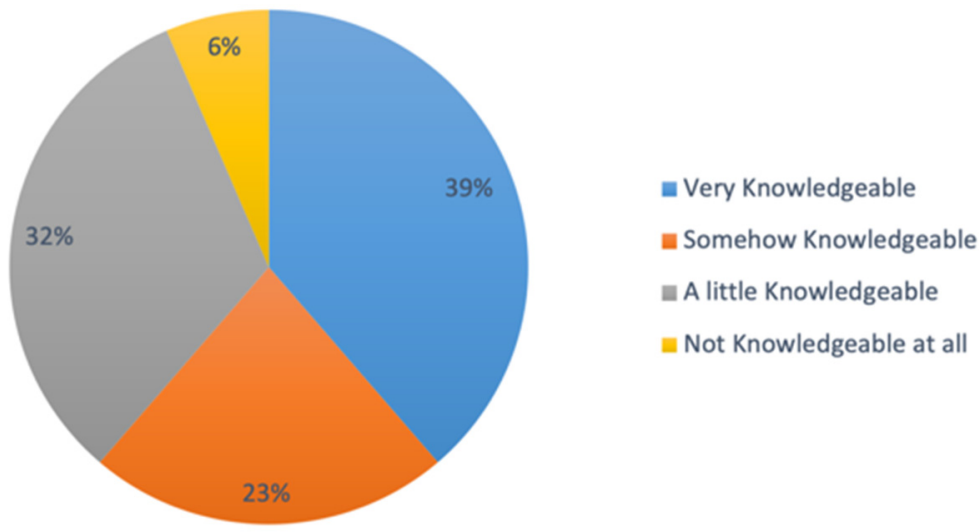

Figure 6: Level of understanding regarding greenhouse effect among the respondents.

the respondents did not have any knowledge of the nature and effects of fossil fuels. Almost two-thirds of the respondents were either very knowledgeable or somewhat knowledgeable about the nature and impact of fossil fuels on the environment. Respondents are aware of the fossil fuels effects on climate change, however, less number of respondents were aware of this compared to the number of respondents who were aware of greenhouse gases effects on climate change.

At last, we have checked the statistics about respondent's awareness on knowledge of causes and impacts of climate change. Fig. 8 shows the level of knowledge of the respondents regarding climate changes and their impact on human lives. $14 \%$ of the respondents were knowledgeable in both causes and effects of climate conditions, $21 \%$ were identified to have good knowledge of the causes of climate changes but were not aware of its impact on the environment and human lives. Thus, $33 \%$ of the respondents were clueless about the causes 
and impact of climate changes. Most individuals showed little knowledge of climate changes, and they were less informed about its causes and effects. The lack of knowledge and awareness regarding climate change resulted in unsatisfactory recommendations from the respondents on mitigating the impacts of climate change.

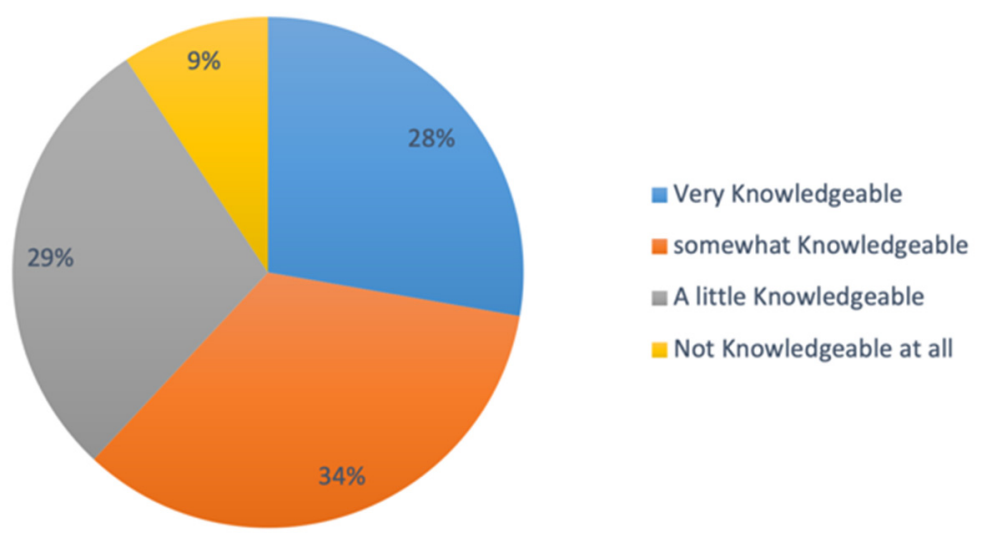

Figure 7: Awareness of respondents on the nature and effect of fossil fuels on the environment.

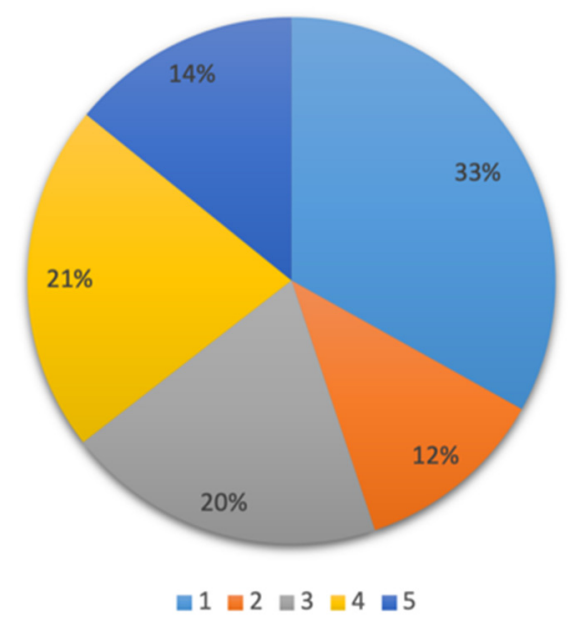

Figure 8: Awareness of knowledge of causes and impact of climate change among the respondents.

Altogether, our results suggested that the respondents were worried about the climate changes and know about the impacts of greenhouse gases and fossil fuels on the environment, however, less than quarter of the respondents were only aware of the knowledge of causes and impacts of climate change. Although the respondents completed college or university level education, most of them are not fully aware of causes and impacts of climate change 
and this may be due to lack of promoting awareness on causes of climate change by the government or lack of communication among the Saudi people to get the knowledge on it.

\section{DISCUSSION}

The responses from the questionnaire displayed the level of knowledge and awareness of the people about climate change in Dammam Saudi Arabia. The people of the city of Dammam showed a moderate level of understanding of climate change and the causes and effects of global warming, and their proposed solutions on how to tackle the problems were inadequate, appropriately the inadequacy of their knowledge is due to their reliance on traditional sources of knowledge about climate change. A huge flaw of such sources is that they have little impact on people's attitudes or behaviors because they do not account for the recipient's level of education or background [29]. Almost equal or slightly higher than to quarter of the respondents were either very knowledgeable or somewhat knowledgeable about the nature and impact of fossil fuels on the environment. The study shows that most people do not know that human activities and behavior directly impact the environment and climate. According to Boillat and Berkes [30], climate conditions and environmental behavior are linked to human behaviors. In current study, the major reason behind most individuals not being able to access knowledge on climate change is their use of traditional resources to get climate information. The traditional resources of data are linked to the level of education and ability to read and write [31]. However, modern forms of communication such as social media and YouTube can help even the less educated people acquire the knowledge they want. Better ways of gaining knowledge such as experience and significant elements by the Saudi people will work better than the traditional knowledge sources. The Saudi people's level of knowledge and awareness on climate change can be increased by adopting the channels of communication. The government of Saudi Arabia and other stakeholders need to work together to ensure more people are exposed to knowledge about climate change and global warming. When the number of knowledgeable people increases, it will be easier to handle the climate complications and environmental degradation [32].

Most of the respondents showed moderate knowledge of traditional climate change, such as social media not government or official, and were less aware of the causes and effects of climate change. Saudi governments have to raise awareness and implement policies regarding causes and effects of climate changes [33]. Saudi Arabia could view other countries as models of how local governments can encourage their participation in the reduction of effects of climate changes. The urban environment and climate change need to be looked at mutually. This would mean more inclusive and comprehensive urban planning practices with possible environmental impacts such as land use, transport strategies, waste and water management, green development, public health, and service placement [33]. Local government has also a clear chance to become more aware of climate change, of local mitigation and adaptation efforts, and to help societies to adopt energy efficient lifestyles and reduce household greenhouse gas emissions. Indeed, Saudi Arabia can potentially move toward creating a less oil-centered, more environmentally friendly economy, with the recent launch of its 2030 national vision, which significantly reduces conventional dependency on petroleum [33]. By 2030 the Kingdom is also committed by investing in clean energy projects including solar energy masses to cut the annual energy emissions to 130 million tons [33]. Saudi Arabia also partnered with international stakeholders in the fight against climate change and was part of the international effort. The Paris Agreement, which called on the nations to join forces for a common cause, against climate change and mitigation, was officially endorsed in November 2016 by Saudi Arabia [33]. The Saudi Environmental 
Society is also building a broad base of volunteers and are helping to strengthen the private sector role in environmental issues such as the conservation of nature and wildlife.

\section{CONCLUSION}

The residents of Dammam City, Saudi Arabia, displayed fair knowledge and awareness of the causes and effects of climate changes. The insufficient knowledge and awareness on climate change shown in the study reflected that the city residents had little background information on pollution, global warming, and environmental conservation. The research findings will help in the decision-making processes needed to reduce the adverse effects of climate change and global warming. Further research needs to be done in other regions to identify the percentage of people who are knowledgeable and aware of climate change issues. Research in the future will also need to measure the perception, awareness, and knowledge of different people in the community, for example, farmers. This will give a public portray of the level of knowledge, perception, and awareness of Saudi citizens on climate change. The scope of the study should be widened to obtain a clearer picture of the level of knowledge and awareness regarding climate change of the entire population of Saudi Arabia.

\section{ACKNOWLEDGEMENT}

The author greatly acknowledges the support provided by Imam Abdulrahman Bin Faisal University, Dammam, Saudi Arabia.

\section{REFERENCES}

[1] Devine-Wright, P. \& Quinn, T., Dynamics of place attachment in a climate changed world. Place Attachment, pp. 226-242, 2020. https://www.taylorfrancis.com/chapters/ mono/10.4324/9780203757765-25/dynamics-place-attachment-climate-changedworld-lynne-manzo-patrick-devine-wright.

[2] Abel, D.W. et al., Air-quality-related health impacts from climate change and from adaptation of cooling demand for buildings in the eastern United States: An interdisciplinary modeling study. PLOS Medicine, 15(7), e1002599, 2018.

DOI: 10.1371/journal.pmed.1002599.

[3] Karimi, V., Karami, E. \& Keshavarz, M., Climate change and agriculture: Impacts and adaptive responses in Iran. Journal of Integrative Agriculture, 17, pp. 1-15.

DOI: 10.1016/S2095-3119(17)61794-5.

[4] Luo, M., Sa, C., Meng, F., Duan, Y., Liu, T. \& Bao, Y., Assessing extreme climatic changes on a monthly scale and their implications for vegetation in Central Asia. Journal of Cleaner Production, 271, 122396, 2020. https://www.mdpi.com/2077-6Nov.0472/487/pdf.

[5] Irby, I.D., Friedrichs, M.A., Da, F. \& Hinson, K.E., The competing impacts of climate change and nutrient reductions on dissolved oxygen in Chesapeake Bay. Biogeosciences, 15(9), pp. 2649-2668, 2018. https://bg.copernicus.org/articles/15/2649/2018/.

[6] Beas-Luna, R. et al., Geographic variation in responses of kelp forest communities of the California current to recent climatic changes. Global Change Biology, 26, pp. 6457-6473, 2020. DOI: $10.1111 /$ gcb.15273.

[7] United Nations News, UN emissions report: World on course for more than 3 degree spike, even if climate commitments are met, 2019. https://news.un.org/en/story/2019/ 11/1052171. Accessed on: 13 Aug. 2021.

[8] Intergovernmental Panel on Climate Change (IPCC), IPCC Fourth Assessment Report: Climate change, 2007. https://www.ipcc.ch/assessment-report/ar4/. 
[9] UNESCO, Climate change education and awareness, 2018. https://en.unesco.org/themes/addressing-climate-change/climate-change-educationand-awareness.

[10] Hoegh-Guldberg, O. et al., The human imperative of stabilizing global climate change at $1.5^{\circ}$ C. Science, $\mathbf{3 6 5}$, p. 6459,2019 . DOI: $10.1126 /$ science.aaw6974.

[11] Watts, N. et al., The 2019 report of the lancet countdown on health and climate change: ensuring that the health of a child born today is not defined by a changing climate. Lancet, 394, pp. 1836-1878, 2019. DOI: 10.1016/S0140-6736(19)32596-6.

[12] Semenza, J.C. et al., Public perception of climate change: Voluntary mitigation and barriers to behavior change. American Journal of Preventive Medicine, 35(5), pp. 479487, 2008. DOI: 10.3390/cli7050061.

[13] Darfaoui, E.M. \& Al-Assiri, A., Response to climate change in the Kingdom of Saudi Arabia. A report prepared for FAO-RNE, 2013.

[14] Williams, J.J. \& Newbold, T., Local climatic changes affect biodiversity responses to land use: A review. Diversity and Distributions, 26, pp. 76-92, 2020.

DOI: $10.1111 /$ ddi.12999.

[15] Wolf, J. \& Moser, S.C., Individual understandings, perceptions, and engagement with climate change: Insights from in-depth studies across the world. Wiley Interdisciplinary Reviews: Climate Change, 2(4), pp. 547-569, 2011.

DOI: $10.1002 /$ wcc. 120 .

[16] Mu'azu, N.D., Abubakar, I.R. \& Blaisi, N.I., Public acceptability of treated wastewater reuse in Saudi Arabia: Implications for water management policy. Science of the Total Environment, 721, 137659, 2020.

[17] Macrotrends, Ad-Dammam, Saudi Arabia Metro Area Population 1950-2021, 2021. https://www.macrotrends.net/cities/22416/ad-dammam/population. Accessed on: 3 Mar. 2021.

[18] Siegel, F.R., Adaptations of coastal cities to global warming, sea level rise, climate change and endemic hazards. Springer, 2019.

https://www.springer.com/gp/book/9783030226688.

[19] Kortlick, J.W.K.J.W. \& Higgins, C.C.H.C.C., Organizational research: Determining appropriate sample size in survey research appropriate sample size in survey research. Information Technology, Learning, and Performance Journal, 19(1), p. 43, 2001. http://citeseerx.ist.psu.edu/viewdoc/download?doi=10.1.1.486.8295\&rep=rep1\&type $=$ pdf.

[20] Ghaljaie, F., Naderifar, M. \& Goli, H., Snowball sampling: A purposeful method of sampling in qualitative research. Strides in Development of Medical Education, 14(3), 2017.

http://sdme.kmu.ac.ir/article_90598_3632edfb2e97c38d73c0bdea8753195c.pdf.

[21] Dusek, G., Yurova, Y. \& Ruppel, C., Using social media and targeted snowball sampling to survey a hard-to-reach population: A case study. International Journal of Doctoral Studies, 10, pp. 279-299, 2015. DOI: 10.28945/2296.

[22] Emhj, Gender inequity in Saudi Arabia and its role in public health. WHO EMRO, EMRO Landing, Front page, 2010. https://www.emro.who.int/emhj-volume-16-2010/ volume-16-issue-1/article19.html.

[23] Almulhim, A.I. \& Abubakar, I.R., Understanding public environmental awareness and attitudes toward circular economy transition in Saudi Arabia. Sustainability, 13, p. 10157, 2021. DOI: 10.3390/su131810157. 
[24] Kennedy-Shaffer, L., Qiu, X. \& Hanage, W.P., Snowball sampling study design for serosurveys early in disease outbreaks. American Journal of Epidemiology, 2021. DOI: 10.1093/aje/kwab098.

[25] Nunnally, J.C. \& Bernstein, I.H., Psychometric Theory, 3rd ed., McGraw-Hill: New York, 1994.

[26] Carmines, E.G. \& Zeller, R.A., Reliability and Validity Assessment, SAGE: Newbury Park, CA, 1979.

[27] Cohen, J., Statistical Power Analysis for the Behavioral Sciences, 2nd ed., Routledge, 1988.

[28] Ricciardi, A. et al., Four priority areas to advance invasion science in the face of rapid environmental change. Environmental Reviews, 29(999), pp. 1-23, 2021. https://cdnsciencepub.com/doi/full/10.1139/er-2020-0088.

[29] Pabón-Caicedo, J.D. et al., Observed and projected hydroclimate changes in the Andes. Frontiers in Earth Science, 8, 2020. DOI: 10.3389/feart.2020.00061.

[30] Boillat S. \& Berkes, F., Perception and interpretation of climate change among quechua farmers of Bolivia: Indigenous knowledge as a resource for adaptive capacity. Ecology and Society, 18(4), p. 21, 2013. DOI: 10.5751/ES-05894-180421.

[31] Ning, G., Yim, S.H.L., Yang, Y., Gu, Y. \& Dong, G., Modulations of synoptic and climatic changes on ozone pollution and its health risks in mountain-basin areas. Atmospheric Environment, 240, 117808, 2020. https://www.x-mol.com/paperRedirect/1288530974425661440.

[32] Orton, P. et al., New York city panel on climate change 2019 report. Chapter 4: Coastal flooding. Annals of the New York Academy of Sciences, 1439(1), pp. 95-114, 2019. https://collaborate.princeton.edu/en/publications/new-york-city-panel-on-climatechange-2019-report-chapter-4-coast.

[33] Saghir, B., Climate Change in Saudi Arabia: Rethinking the Role of Local Government, KSCLG.org, 2021. http://www.ksclg.org/en/publication-project/climatechange-in-saudi-arabia-rethinking-the-role-of-local-government/. Accessed on: 26 Sep. 2021. 